\title{
¡CÓMO HACEN FRENTE LAS COSAS A LAS MIRADAS! WALTER BENJAMIN Y LA MIRADA DE LO URBANO
}

\author{
Claudia Supelano-Gross* \\ doi:10.11144/Javeriana.uph31-62.wbmu
}

\begin{abstract}
RESUMEN
A lo largo de su obra, Walter Benjamin identificó el potencial y alcance de lo urbano en el desarrollo de su reflexión filosófica. Por ello, este artículo pretende ahondar en el Benjamin lector de Franz Hessel y Charles Baudelaire para así examinar algunas de las repercusiones que su interpretación tuvo en los recorridos que llevó a cabo de Berlín y París y que dan lugar a una filosofía que aboga por la recuperación de la categoría filosófica de espacio frente a la privilegiada categoría del tiempo. Solo así es posible sostener que es en la literatura donde Benjamin encuentra el punto de apoyo para desarrollar una teoría de la experiencia arraigada en la vivencia de la ciudad que busca elevar lo cotidiano, lo fragmentario, lo breve y lo aparentemente insignificante.
\end{abstract}

Palabras clave: Walter Benjamin; Charles Baudelaire; Franz Hessel; ciudad; espacio

\footnotetext{
${ }^{*}$ Universidad de Salamanca, Salamanca, España.

Recibido: 07.08.13 ACEPTADO: 21.11.13

DiSPONIBLE EN LÍNEA: 30.06 .14

Para citar este artículo: Supelano-Gross, C. (2014). ¡Cómo hacen frente las cosas a las miradas! Walter Benjamin y la mirada de lo urbano. Universitas Philosophica, 31(62), 147168. ISSN 0120-5323; ISSN en línea 2346-2426; doi:10.11144/Javeriana.uph31-62.wnmu
} 


\title{
HOW THINGS FACE TO LOOKS! WALTER BENJAMIN AND THE LOOK OF THE URBAN
}

\author{
Clauda Supelano-Gross
}

\begin{abstract}
Throughout his work, Walter Benjamin identified the potential and range of the city in the development of his philosophical thought. Taking this into account, this article pretends to delve into Benjamin as a reader of Franz Hessel and Charles Baudelaire in order to analyze some of the consequences of his interpretation within the journeys he made through Berlin and Paris, that led him to a philosophical posture that stands for the recovery of space as a philosophical category rather than the privileged category of time. These considerations allow sustaining literature as the supporting point where Benjamin develops a theory of experience linked to the city, which pretends to raise the quotidian, the fragmentary, the brief, and the apparently insignificant.
\end{abstract}

Key words: Walter Benjamin; Charles Baudelaire; Franz Hessel; city; space 
Y junto con el café tomas quién sabe cuántas cosas: tomas toda la mañana, la mañana de este día y a veces también la mañana perdida de la vida.

(Benjamin, 1992: 87)

\section{Constelación urbana. Walter Benjamin y la ciudad}

ABordar El TEMA DE LA CIUDAD desde una perspectiva filosófica se presenta como una tarea sumamente compleja y, a la vez, necesaria. La ciudad es un espacio transformador y transformado, construido y destruido; es un libro abierto para quien quiera transitar por sus páginas. Teniendo esto en cuenta, parece que no hay manera de "escapar" de la ciudad; lo urbano no solo determina y define, sino que, en cuanto tal, permite una mejor comprensión del propio ser humano. Aun así, las reflexiones filosóficas en torno a la ciudad parecen insuficientes, y aunque muchos pensadores han tratado dicha temática, pocos han profundizado en ella. En cambio, han sido artistas, sociólogos, escritores, fotógrafos, cineastas, etc., quienes se han atrevido a asumir la responsabilidad de mostrar la importancia de su tratamiento y la complejidad de su naturaleza.

Este abandono de la ciudad como objeto filosófico, pone de relieve lo que José Luis Pardo ha denominado un "desplazamiento del espacio a favor del tiempo en tanto que categoría filosófica" (Pardo, 1990:23). Pese a este desplazamiento, dado que el hombre está siempre situado, el espacio como categoría fundamental permite reorientar la reflexión filosófica en torno a la ciudad, "traer a la superficie de la interpretación la espacialidad fundamental y exhaustiva de la vida humana, aunque frecuentemente esta haya sido enterrada o relegada a segundo plano" (Soja, 2008: 20). Por esto, formular la pregunta en torno a la ciudad se presenta como una necesidad, como urgencia de una cuestión que es muy cercana, una cuestión a la que no es preciso llegar, sino "en la que estamos ya desde antes" (Soja, 2008: 20).

Si esto es así, la importancia de la obra de Walter Benjamin se hace evidente, en tanto que la complejidad de su pensamiento, así como sus más íntimos intereses filosóficos, se entrecruzan con la mirada y la experiencia de lo urbano. Y, si bien en Benjamin no hay en un estudio sistemático de la "ciudad", como tampoco una única manera de abordarla, esta es como un eco, una sombra, siempre presente en su obra. 
Como si se tratara de una versión moderna del legado socrático, Benjamin asume que para hacer filosofía hay que estar en la ciudad, puesto que toda reflexión parte y se encuentra en ella. Con tal fin, postuló una mirada de la ciudad de todas las maneras posibles: a través de postales, relatos citadinos, viajes, recuerdos de la infancia, libros acerca de las grandes metrópolis, calles, mapas, planos, transeúntes, y cuanto objeto le permitiera acercarse a la ciudad. En este recorrido, la literatura y París tuvieron un lugar privilegiado y, en él, Charles Baudelaire fue su incansable guía. Quizás porque, como Sócrates, Baudelaire también concebía la ciudad como el lugar del conocimiento en tanto escenario humano del shock, donde confluyen lo visible y lo invisible, lo agradable y lo horrible, donde tiene cabida la auténtica reflexión y el arte. En una carta de 1855, escribe Baudelaire:

Querido Desnoyers, me pides unos versos sobre la Naturaleza, ¿verdad? Bosques, castaños, prados, insectos, incluso el sol ¿no? Lo siento, pero ya sabes que soy incapaz de enternecerme ante los vegetales y mi alma se rebela ante esa nueva religión que siempre tendrá algo de shocking, para alguien realmente espiritual, me temo. Nunca creeré que el alma de los dioses habite en las plantas, y aunque allí habitara, me importan más bien poco, pasando a considerar la mía mucho más preciosa que la de esas hortalizas sacralizadas ${ }^{1}$.

Estas afirmaciones, así como los temas, la poética y figura de Charles Baudelaire, obsesionaron a Benjamin, pues en él y en el París de su época vio la posibilidad de reconstrucción histórico-crítica de la sociedad capitalista del siglo XIX que tanto le interesaba ${ }^{2}$. En Benjamin, al igual que en Baudelaire, no parece haber un interés por lo natural, sino más bien el pleno reconocimiento de una nueva situación, a saber: la ciudad es el bosque de la modernidad. Por ello, no es extraño que Benjamin dedicara varias obras y fragmentos a la reflexión en torno al poeta francés, como tampoco que, a través de él, reivindicara la reflexión de la ciudad desde y en ella misma. Justamente, este punto es el que interesa destacar aquí, en la medida en que posibilita la comprensión de la preocupación benjaminiana en torno a la ciudad. Ahora bien, hay que tener presente que, si bien París ocupó un lugar

\footnotetext{
${ }^{1}$ Carta de 1855, subrayado de Baudelaire. Véase: Azúa, 1999: 55.

${ }^{2} \mathrm{Si}$ bien no es el objetivo del presente artículo ahondar en este tema, es importante tener en cuenta que la reconstrucción histórico-crítica que pretende Benjamin y su relación con Baudelaire, tienen en su base una concepción de la historia muy específica expuesta en las célebres Tesis sobre la filosofía de la historia.
} 
central en la reflexión benjaminiana, esta no se limita ni se refiere únicamente a dicha ciudad. Por el contrario, es el resultado de la articulación de diversos escenarios que forman, por usar un término benjaminiano, una constelación urbana.

El uso de tal término no es azaroso. Al contrario, en Benjamin, constelación tiene un objetivo muy específico: poner de relieve que en el trato con la realidad lo importante radica en la autosuficiencia de los objetos y los fenómenos, es decir que estos sean únicos y que no se sometan o queden diluidos en una cadena de fenómenos, unos tras otros. La fascinación por los objetos y las correlaciones entre ellos es fundamental en tanto que presenta la filosofía benjaminiana como interpretación de singularidades, como una filosofía del fragmento, alejada de toda concepción sistemática ${ }^{3}$. Y aunque en las constelaciones las estrellas son independientes, no tienen ninguna relación aparente entre sí, la observación ha llevado a establecer líneas de unión que permiten advertir nuevas formas. Esto se traduce en una manera de abordar las cosas caracterizada por el extrañamiento, en el que la noción de experiencia tiene un papel fundamental. Por estas características y por ser propio del proyecto benjaminiano, el modelo de constelación permite establecer un mosaico conformado por cuatro ciudades ${ }^{4}$-Berlín, Nápoles, Moscú, París- independientes entre sí y pensadas desde distintas perspectivas.

\footnotetext{
${ }^{3}$ De acuerdo con Hannah Arendt, esa interpretación de singularidades viene determinada por un interés en "la correlación entre una escena callejera, una especulación sobre el mercado de cambios, un poema, un pensamiento, con la línea oculta que los mantiene unidos y le permite al historiador o al filólogo reconocer que todos deben situarse en el mismo periodo" (Arendt, 2001: 149). En la misma línea, Rafael Gutiérrez Girardot señala que, justamente, en este sentido se puede afirmar que hay en Benjamin una continuación y radicalización del postulado de "superación de la distancia entre la palabra y la cosa" que estaba presente en Lichtenberg, Hofmannstal, Husserl y Rilke entre otros, en tanto que este "giro hacia las cosas fue consecuencia del fin de la metafísica, del fin de los pilares del sistema, de la teoría del conocimiento con sus dos polos seguros sujeto y objeto". (Gutiérrez, 2005: 108)

${ }^{4}$ No hay que olvidar que Benjamin escribió sobre muchas otras ciudades (Ibiza, San Giminiagno, Capri, Berna, etc.), pero lo cierto es que son estas cuatro urbes las que permiten establecer de manera más clara una dialéctica para indagar las preocupaciones estéticas de Benjamin, en las que sensibilidad y conocimiento, así como una particular teoría de la experiencia -que a su vez está relacionada con una específica teoría del conocimientoponen de relieve que la ciudad no es un tema concomitante en su obra, sino que varios de sus planteamientos subyacen a sus recorridos urbanos.
} 
El tratamiento benjaminiano de estas ciudades ha sido estudiado desde otras perspectivas por Susan Buck-Morss (1995) y retomado por Martin Kohan (2007). Buck-Morss establece un esquema de coordenadas espaciales, y se apoya en la noción de apropiación de un lugar que Benjamin expone en su Diario de Moscú $u^{5}$. Cuatro puntos cardinales que, de acuerdo con la autora, guían la indagación benjaminiana de la ciudad: Berlín al norte, París al oeste, Moscú al este y Nápoles al sur. París y Moscú, origen y final de la sociedad burguesa; Nápoles, infancia mítica; Berlín, infancia del autor. Basándose en este esquema, Kohan habla de una "Zona Urbana" que se configura como una ciudad nueva, tan real como imaginada y que, según el autor, "cobra existencia en el recorrido de lectura por los textos de Benjamin" (Kohan, 2007: 29). Kohan, siguiendo a Buck-Morss, afirma así que se trata de cuatro ciudades que hacen referencia a distintos tiempos y escritos: un nivel temporal y uno social y personal. Dos ciudades de ruptura: la revolución francesa (París) y la proletaria (Moscú). Esta línea de análisis es complementada por Claudia Kerik (Cfr. Kerik, 2007) cuando señala que estas cuatro ciudades determinan cuatro tipos de escritura en Benjamin: crítico (París), diario de viaje (Moscú), reseña de turista (Nápoles) y autobiográfico (Berlín).

A pesar de las importantes aportaciones de estos autores -el texto de Buck-Morss es considerado un clásico y ha dado pie a múltiples discusionesno se puede pasar por alto que hay más relaciones entre estas ciudades, establecidas además por el propio Benjamin, que no se agotan en el esquema de puntos cardinales, pues tal y como el propio autor afirma, "este es solo el principio en la orientación" (Benjamin, 1991: 32). Precisamente por esta razón, la figura de la constelación resulta más adecuada en tanto que posibilita hablar de una teoría de la ciudad en sentido amplio sin caer en simplificaciones. Adicionalmente, hay que tener en cuenta que estos modelos no parecen responder del todo al método utilizado por el filósofo, esto es, a la recolección y puesta en evidencia de materiales y observaciones para que estas sean interpretadas. En este sentido, no es posible limitar el tema de lo

\footnotetext{
${ }^{5}$ En este texto afirmaba Benjamin: «para poseer un sitio hay que haber entrado en él desde los cuatro puntos cardinales, e incluso haberlo abandonado en esas mismas direcciones. De lo contrario le puede saltar a uno, inopinadamente, tres o cuatro veces, en mitad del camino antes de haberse preparado para toparse con él. En un segundo estadio, uno ya lo busca y lo utiliza como punto de orientación». (Benjamin,1991:32).
} 
urbano a un esquema cardinal de este tipo, que parece simplificarlo ${ }^{6}$. Por ello, siguiendo lo que se puede rastrear en los escritos benjaminianos, más que de puntos cardinales o de una "zona" casi literaria, se podría decir que estas ciudades forman una constelación urbana que se presenta como un todo complejo, compuesto de diversos elementos que permiten la consideración de la ciudad como objeto estético en sentido amplio.

Sin embargo, no es el objetivo del presente artículo analizar de manera detallada la totalidad de la constelación, ni cada uno de los posibles recorridos urbanos; por el contrario, lo que se pretende aquí es ahondar en dos de ellos: Berlín y París, en los que, sin duda, la literatura ejerce mayor influencia a través de la identificación llevada a cabo por Benjamin -en tanto lector de la obra de Franz Hessel y Charles Baudelaire-, de su potencial cognitivo y filosófico.

\section{Berlín, ciudad (re)creada}

LA REFLEXIÓN BENJAMINIANA en torno a Berlín la componen, principalmente, dos obras: Infancia en Berlín hacia 1900 y Crónica de Berlín. Ambas están relacionadas con un proyecto que se remonta a 1931, año en que Benjamin se comprometió con la Literarische Welt para escribir, desde octubre de 1931 hasta marzo de 1932, cuatro Crónicas de Berlín. No obstante, al iniciar la compleja labor de hablar de su ciudad natal, Benjamin consideró que el material no debía agotarse en el proyecto inicial (Cfr. Benjamin, 1996: 19) y convirtió algunas de las notas de Crónica de Berlín en Infancia en Berlín hacia 1900.

La particularidad que caracteriza a los textos que componen este primer recorrido, estriba en su determinación por dos aspectos: de un lado, el hecho de que Berlín sea la ciudad natal de Benjamin; de otro, la decisión del autor de jugar con datos autobiográficos ${ }^{7}$. De acuerdo con esto, la ciudad es abordada a partir de las experiencias de la infancia, pues para el filósofo alemán

\footnotetext{
${ }^{6}$ La simplificación aquí señalada fue puesta de relieve por Gutiérrez Girardot en uno de sus últimos escritos al referirse al texto de Kohan como una "construcción ingeniosa, pero elemental y parcial" (Gutiérrez, 2005: 110). Pese a que la edición aquí citada del texto de Kohan es de 2007, una primera edición apareció en Argentina en 2004 (Cfr. Kohan, 2004).

${ }^{7}$ No hay que olvidar que si en Crónica de Berlín Benjamin hace referencia explícita a varios datos autobiográficos, en Infancia en Berlín hacia 1900, intenta evitarlos.
} 
[E]l estímulo superficial, lo exótico, lo pintoresco solo tiene efecto en el extranjero. Para retratar una ciudad, un nativo necesita otros motivos -más profundos-, los del que viaja hacia el pasado en lugar de en la distancia. El libro de un nativo sobre su ciudad siempre se relacionará con los recuerdos, el escritor no ha pasado allí su infancia en vano (Benjamin, 1997: 215).

Ahora bien, no se trata de que la ciudad sea un mero escenario en el que transcurren las anécdotas, por el contrario, son estas últimas las que están al servicio del "conocimiento de la ciudad". A este respecto cabe recordar lo que Benjamin afirma al inicio de Crónica de Berlín: "quiero rememorar aquí a aquellos que me han iniciado en el conocimiento de la ciudad" (Benjamin, 1996: 188). En este sentido, el autor establece una doble vía de conocimiento de la urbe. Por un lado, aquellos guías y, por otro, el acto de rememorar. Si bien Benjamin anuncia cinco guías fundamentales, en su escrito solo deja entrever cuatro, a saber: las niñeras, las prostitutas, el extravío y la obra de Franz Hessel. Este último ejerció una fuerte influencia en el filósofo alemán con su libro Paseos por Berlín, y en Infancia en Berlín es evocado como su compañero de travesía:

Descubrí más tarde rincones nuevos: he completado mi conocimiento de los otros... treinta años más tarde, cuando un geógrafo, un natural de Berlín, se unió a mí tras una larga ausencia de ambos en la ciudad. Sus pasos surcaron ese jardín en el que él sembraba el grano del silencio (Benjamin, 1996: 25).

Hessel fue, precisamente, el primero en referirse al potencial cognitivo de la ciudad, como en transmitirlo a través de la literatura. De ahí que Benjamin tomara de la lectura de sus obras dos mecanismos de representación urbana. El primero asume a Berlín como ciudad conocida, rememorada, recreada -es la ciudad que tantas veces recorrió de pequeño-; el segundo, como ciudad ajena, creada. A partir del primer mecanismo Benjamin configura una autobiografía espacial, pues como señala Adorno en el epílogo a Infancia en Berlín, "el contrapeso subjetivo a las masas de material que reunió para la proyectada obra de los pasajes de París" (Benjamin, 1996: 220). Sin embargo, la rememoración no se agota en el deseo autobiográfico sin más, de hecho, para Benjamin, se trata de que

[L]os recuerdos, incluso cuando se extienden en detalles, no siempre representan una autobiografía. Y con toda seguridad esto no lo es ni siquiera en lo referente a los años en Berlín [...] pues la autobiografía tiene que ver con el transcurso del tiempo y con aquello que constituye 
el constante fluir de la vida. En cambio, aquí se trata de un espacio, de momentos y de inconstancia (Benjamin, 1990: 212).

Precisamente, en este punto, el propio autor da la clave de cómo ha de entenderse su crónica: no se trata de un recuento autobiográfico sino de pensar el espacio, pensar la ciudad, lo cual se encuadra perfectamente en esa recuperación de la espacialidad humana como fundamento de la reflexión filosófica en torno a la ciudad y frente a la privilegiada categoría del tiempo ${ }^{8}$. Evidentemente, para Benjamin, el acto de rememorar tiene un objetivo epistemológico, puesto que "en el recuerdo aprendemos la nostalgia como principio de conocimiento". Esto, a su vez, remite a una particular concepción de la experiencia, lo que explica que en 1940 Benjamin escribiera a Adorno: "por qué ocultaré que encuentro en mis recuerdos de infancia la raíz de mi "teoría de la experiencia"” (Adorno, 1998: 25).

En este sentido, es posible afirmar que Benjamin habla desde el recuerdo de lugares, hechos y objetos concretos, para configurar desde ellos un Berlín determinado por el extrañamiento del complejo en que la ciudad, en apariencia homogénea, se convierte. Por ello, lo que muestra Benjamin es que en la experiencia de conocimiento de la ciudad cualquier objeto es fundamental y, por ende, tal y como afirma Adorno, es preciso "contemplar todos los objetos tan cerca como fuera posible, hasta que se volvieran ajenos y como ajenos entregaran su secreto" (Adorno, 1995: 70). Este método de consideración de lo fragmentario, de lo nimio, de lo cotidiano, será definido por Benjamin en sus escritos posteriores como fisionómico, término que toma del propio Hessel para quien su libro sobre Berlín debía ser entendido “como fisionomía de la ciudad" (Hessel, 1997: 211).

De lo anterior se sigue el uso del segundo mecanismo que procura introducir una forma de abordar la ciudad en la que se pretende no conocerla. Este se basa en la intención expuesta por Hessel de "volver a mirar la ciudad en la que vivo como lo hice la primera vez o encontrar la forma de volver

\footnotetext{
${ }^{8}$ En este sentido, y sumado a lo ya dicho, encontramos en Benjamin una primera intención de aquello que Edward Soja ha definido como Postmetrópolis "en tanto acto de (re) compensación que intenta terminar con el privilegio del tiempo sobre el espacio, fuertemente arraigado en los estudios urbanos, evitando solo invertir, sin embargo, el orden del privilegio, es decir, evitando subordinar el tiempo y la historia a una determinación espacial" (Soja, 2008: 36-37).

${ }^{9}$ Manuscrito 878 del archivo Benjamin (Benjamin, 1996: 293).
} 
a hacerlo" (Hessel, 1997: 33). Dicho mecanismo viene posibilitado por un extrañamiento que busca que la ciudad se revele, revelación que solo es posible una vez que hay distancia, la cual se traduce, en un aprender a perderse.

Perderse en una ciudad -igual que uno se pierde en un bosque- es algo que requiere ya una formación muy distinta. Para ello, letreros y nombres de las calles, transeúntes, tejados, quioscos o tabernas tienen que hablarle al callejeante como ramas que crujen en el bosque bajo sus pies, como el espantoso grito de un avetoro a lo lejos, como la súbita calma de un claro del bosque en cuyo centro un lirio ha brotado (Benjamin, 1996: 190).

Si bien están íntimamente relacionados, este aprender a perderse ha de diferenciarse del no orientarse, pues de lo que se trata es de "incitar a quienes pretenden luchar contra el anquilosamiento de la imaginación a que no se olviden de olvidar a fin de no perder la memoria y la curiosidad" (Augé, 1998: 104). El olvido, para Benjamin, devuelve al presente, aunque se conjugue en todos los tiempos: en futuro, para vivir el inicio; en presente, para vivir el instante; en pasado, para vivir el retorno. En el aprender a perderse, por tanto, es fundamental el papel de la infancia, tal y como el propio Benjamin lo configura. Y esto es así porque la tarea de la infancia es introducir el nuevo mundo en el espacio simbólico, pues "el niño puede hacer aquello de lo que el adulto es completamente incapaz: reconocer lo nuevo [...] Toda infancia describe estas nuevas imágenes para incorporarlas al patrimonio de imágenes de la humanidad" (Benjamin, 2005: K1a, 3, 395) ${ }^{10}$. Se trata, por tanto, del correlato de la vida olvidada que presentaba Proust, en el que el adulto, a través de la mirada regresa a la infancia "abriendo el abanico del recuerdo" (Benjamin, 1996: 191) $)^{11}$.

Con todo, no es de extrañar que en varias ocasiones el autor haga referencia a su propio extravío, ni que aluda a su falta de orientación y de memoria. Justamente esta carencia se presenta como una especie de

\footnotetext{
${ }^{10}$ Las referencias relativas al Libro de los Pasajes (Benjamin, 2005) incluirán la letra y el número del Konvolut correspondiente previo a la página de la versión española a fin de facilitar su localización.

${ }^{11}$ A este respecto, afirma Rafael Gutiérrez Girardot: "sus descripciones de ciudades no se limitan al objetivo trazo literario, sino que traducen, al hilo del recuerdo, su experiencia del tiempo y del espacio y proyectan una filosofía de la historia: el pasado, recuperado en el recuerdo, es esencialmente abierto y la protoforma del futuro" (Gutiérrez, 1965: 15).
} 
resistencia fundamental, pues "quién sabe cuánto de lo que hoy constituye mi relación personal con las calles de la ciudad se fundamenta en esta resistencia" (Benjamin, 1996: 193). El perderse en la ciudad consiste, entonces, en crear distancias, para lo cual la experiencia de haberse ausentado -experiencia compartida por Hessel y Benjamin- es fundamental. Precisamente, es en este punto donde se establece una primera conexión con la segunda ciudad que incumbe al presente artículo: “[E]stas artes de perderse me las ha enseñado París" (Benjamin, 1996: 193). Esta conexión es reforzada si se tiene en cuenta que en la base de la afirmación benjaminiana se encuentra su relación con Hessel, con quien tradujo a Baudelaire y a Proust, y quien dedicó algunas obras a las calles parisinas ${ }^{12}$.

\section{París, ciudad recorrida}

EL TRATAMIENTO BENJAMINIANO DE LA CIUDAD es desarrollado de manera más amplia en los escritos en torno a París. Muchas de sus reflexiones encuentran en esta ciudad no solo su punto de partida sino también de llegada. Por ello, son varios los textos que conforman el entramado de este segundo recorrido urbano: París, la ciudad en el espejo (1929), los dos resúmenes de Paris capital del siglo XIX (1935), El París del segundo imperio en Baudelaire (1938), Sobre algunos motivos en Baudelaire (1939) y las múltiples referencias a la capital francesa en el inacabado Libro de los Pasajes (19271937), entre otros. En cada texto se ofrece una variedad de aproximaciones a lo urbano, tan diversas como la manera en la que el propio Benjamin

\footnotetext{
${ }^{12}$ La relación dialéctica entre los textos (ciudades) de Berlín y París permite identificar un modelo urbano de uno de los temas más tratados y discutidos por Benjamin, a saber: el del aura. Berlín puede verse como ejemplo de ciudad en la que todavía es posible lo aurático, si se tiene en cuenta la definición del aura como "manifestación irrepetible de una lejanía por cercana que esté". En París, en cambio, acontece la pérdida del aura tal y como lo anticipara Baudelaire. Al respecto Benjamin afirma: "cuanto más consciente de esto es Baudelaire, tanto más certeramente se inscribe la decadencia del aura en su obra lírica [...] Baudelaire describe ojos de los que se podrían decir que han perdido su capacidad de mirar [...] es evidente que el ojo del hombre de la gran ciudad está sobrecargado con funciones de seguridad [...] la mirada atenta a la seguridad prescinde de abandonarse soñadoramente a la lejanía" (Benjamin, 2008: 121). Se refiere aquí Benjamin a la experiencia de shock descrita por Baudelaire, pues si en París dicha experiencia imposibilita la memoria, en Berlín pasa lo contrario: todavía es posible aprender a perderse. Si bien el tema del aura se escapa del ámbito del presente estudio, esta pequeña mención deja ver la conexión e importancia de lo urbano con los planteamientos benjaminianos más conocidos.
} 
"recorrió" esta ciudad. En líneas generales, son tres los aspectos que determinan radicalmente esta mirada de lo urbano: la estancia prolongada en la Biblioteca Nacional de París, la vivencia callejera de la ciudad y la fascinación por Charles Baudelaire.

Un primer aspecto que salta a la vista en relación con el tratamiento de París es la importancia que Benjamin otorgó a su estancia en la Biblioteca Nacional y a las lecturas que allí llevó a cabo. La Biblioteca fue una especie de refugio privado desde el cual conocer la ciudad, no escapando a la calle, sino adentrándose en ella de una manera distinta. Ya desde el escrito París, la ciudad en el espejo Benjamin reconocía la importancia de los libros en el conocimiento de esta ciudad, tanto así que para él "no existe ninguna ciudad que esté más íntimamente ligada a los libros que París" (Benjamin, 1992: 72). Por ello, no resulta extraño que el filósofo pasara largas jornadas en la sala de lectura de la Biblioteca Nacional. Este detalle que parece insignificante ha dado pie para que varios de los estudiosos de Benjamin consideren que el recorrido urbano parisino se limita a una cuestión de crítica literaria, más que a una profunda reflexión filosófica. Es el caso Susan Buck-Morss y, continuando con esta línea, Martin Kohan. La tesis que sostienen estos autores es que, en lo que respecta a París, Benjamin reflexionó solo desde la lectura de los textos como representaciones de la ciudad y no desde la consideración de la ciudad como texto. Al respecto afirma Kohan:

La mediación literaria es decisiva en las consideraciones que hace Benjamin sobre París (sobre París, y no sobre las ciudades en general). La perspectiva crítica en la que se sitúa es la del lector que en la Biblioteca Nacional revisa a fondo la bibliografía sobre Baudelaire, no la del flâneur que deambula por las calles y toma sus impresiones (Kohan, 2007: 20).

En este orden de ideas, y de acuerdo con estos autores, Benjamin parecería posicionarse más como un crítico literario que como sujeto de la experiencia en contacto con la ciudad, pues la presentación de París solo estaría fundada en la lectura de las representaciones literarias de la misma. Si bien es cierto que la literatura ocupa un lugar central en el planteamiento en torno a París -no hay que olvidar la importancia que tiene la novela de Louis Aragon Le paysan de Paris, Victor Hugo o, evidentemente, la obra de Charles Baudelaire, por citar los ejemplos más conocidos-, afirmar que la experiencia benjaminiana de esta ciudad es meramente literaria es, a su vez, cuestionable e implica ignorar la coherencia metodológica que el propio Benjamin realizaba. Parece fundamental recordar que en 1926 Benjamin 
pasó varios días en París en compañía de Franz Hessel, quien conocía "las artes de recorrer las calles de París", y de quien las aprendió al tenerlo como guía, según lo afirma en sus escritos sobre Berlín. Otro aspecto sintomático es el hecho de que en el Libro de los Pasajes los materiales referentes a París no se limitan a citas literarias sino que, por el contrario, incluyen, siguiendo con la línea de la mirada cuidadosa como medio de aproximación a la ciudad, referencias a objetos y detalles como la estrechez de las aceras, o los automóviles, o las prostitutas.

Así, es posible afirmar que lo que hay en el París de Benjamin es una tensión entre la lectura de los textos y la vivencia de la ciudad. Tensión que parte de una fascinación personal por la literatura francesa, y también por la consideración de la ciudad como un entramado, como un texto en el sentido etimológico del término, en el que los libros son un elemento constitutivo pero no el único. De esto se sigue que el autor opte por una atenta mirada de la ciudad, pero ya no como el niño de Berlín.

Lo anterior se evidencia con claridad en el pequeño escrito París, la ciudad en el espejo, donde el filósofo alemán concibe a París como "un gran salón de biblioteca atravesado por el río" (Benjamin, 1992: 73), pues considera que no hay monumento alguno ni calle en esta ciudad que no haya servido de inspiración a una obra maestra de la poesía. Así, relaciona a NotreDame con Victor Hugo, la Torre Eiffel con Cocteau o la Opera con Leroux. Y esto es así debido a que, para Benjamin, "esta ciudad se inscribió en forma tan indeleble en la literatura porque en ella misma actúa un espíritu afín al de los libros. ¿No fue ella quien proyectó desde hace tiempo, cual novelista versado, los cautivantes argumentos de su construcción?" (Benjamin, 1992: 73). Sin embargo, París no se agota en este "espectro literario". En sus calles, en el río, la ciudad se refleja en miles de ojos, en miles de objetivos. París es la ciudad-espejo: "liso como un espejo, en el asfalto de sus calles las imágenes se reflejan" (Benjamin, 1992: 73). Y es precisamente allí, en las calles, donde acontece una de las experiencias de la ciudad más importantes, a saber, la del nombrar.

La experiencia del nombrar cobra, para Benjamin, mayor importancia en París por cuanto en dicha ciudad "hay barrios enteros que revelan su secreto en los nombres de sus calles. En la gran plaza delante de la Gare St. Lazare uno está rodeado por media Francia y por media Europa" (Benjamin, 1992: 74). La consideración del nombre como fuente de conocimiento de la 
ciudad es un punto fundamental del callejeo y está íntimamente ligada a la obsesión por lo microscópico que caracteriza el pensamiento benjaminiano. Asimismo, Benjamin reconoce en París uno de los problemas principales que ya había detectado en Moscú: el de la representación de la ciudad. Por ello, afirma que "hay un saber ultravioleta y uno ultrarrojo alrededor de esta ciudad y ninguno de los dos se deja atrapar en forma de libro: son la fotografía y el plano de la ciudad" (Benjamin, 1992: 74).

Sin embargo, no es posible limitar el análisis benjaminiano a la lectura de ciertos textos, sino que, más bien, en París se enfrenta a la complejidad de acercarse a la ciudad, por lo que, tal y como expresa el propio autor en el Libro de los Pasajes, ha de "edificarla también a partir de sus fuentes" (Benjamin, 2005: 113). Una vez establecido esto es posible asumir que en París tienen lugar dos movimientos complementarios y de sentido inverso, tal y como los describe Marc Augé en El viaje imposible:

Uno ve al autor a través de las ciudades que este ha evocado y ve a las ciudades a través de aquellos que las han amado y descrito: fantasmas que gracias a nuestros recuerdos de lecturas continúan recorriendo sus calles y sus plazas [...] a causa de una capacidad de trasmutación, la ciudad es asimismo poética y no sería difícil agregar nombres de poetas a los de los novelistas para expresar la incesante relación que mantienen las palabras de la escritura y el espacio de la ciudad. (Augé, 1998: 109-110)

En la lectura de la obra de Charles Baudelaire, la relación entre las palabras y el espacio de la ciudad se da de forma paradigmática en París. Varios son los puntos que determinan la importancia de Baudelaire en la reflexión llevada a cabo por Benjamin en su intento de reconstrucción filosófica e histórica del siglo XIX -la modernidad, la masa, las correspondencias, el flâneur, los paraísos artificiales, etc. Cada uno constituye un mundo y merecería un análisis propio que escapa al objetivo del presente estudio, pero no hay que perder de vista que todos estos conceptos se enmarcan en un mismo escenario: la ciudad. En esta medida, el interés benjaminiano por la obra de Baudelaire se entiende como una fascinación ante todo estética en la que, a partir de la lectura, sea posible experimentar y conocer la ciudad. No resulta extraño, entonces, que, para Benjamin, la estructura de los versos del poeta francés sea "comparable al plano de una gran ciudad en la que podemos movernos inadvertidos" (Benjamin, 2008: 182), en tanto que lo que hay en ellos es una sensibilidad nueva que se alimenta de la experiencia sensorial de la ciudad. 
Esta experiencia enlaza directamente con la observación cuidadosa de lo pequeño, del detalle, de lo breve, que caracteriza el modo de proceder de Benjamin y que encuentra su correlato en la noción baudelairiana de correspondencias. De acuerdo con Baudelaire, la realidad es como una diosa de dos caras en la que aparentemente todo está dividido y contrapuesto y, sin embargo, se encuentra gobernada por una misteriosa ley de correspondencias que requiere de una sensibilidad capaz de descifrarla. Lo más nimio y vulgar puede referirse a un conocimiento que la filosofía ha buscado en vano. Lo sucio, la violencia, el sexo o la enfermedad forman, por supuesto, parte de las posibles correspondencias, como también la belleza y el amor. Esta ley de correspondencias es entendida por Benjamin como posibilidad dual. Por un lado, como posibilidad de que una palabra sugiera una imagen y "en este caso, la imagen podría determinar el significado de la palabra, o también la palabra el de la imagen" (Benjamin, 2005: J24, 3, 284). Por el otro, como posibilidad de recuperación de la experiencia perdida ${ }^{13}$ en la modernidad que también puede ser entendida como insuficiencia en la capacidad para establecer relaciones entre palabras, objetos e imágenes, es decir, de generar constelaciones que remitan al conocimiento de la historia, pero también de la época ${ }^{14}$.

\footnotetext{
${ }^{13}$ El concepto de pérdida de la experiencia es fundamental a lo largo del pensamiento benjaminiano. Esta pérdida puede entenderse como la limitación de la noción de experiencia a una versión primaria que, al basarse en una concepción científica del mundo, no da cuenta de otros tipos de experiencia. Es el caso de las experiencias ligadas a la asociación de imágenes y al poder cognitivo de los detalles, tan fundamental en la vivencia de la ciudad. Por ello, desde sus escritos más tempranos, bosqueja una propuesta de constitución de un concepto de experiencia más elevado, cuya fundamentación es teórico-epistemológica dentro del marco del pensamiento kantiano, de tal manera que no se trate de una mera experiencia rutinaria, sino de una práctica de la experiencia en sentido profundo que remite a lo que permanece desde lo efímero. Esta nueva noción de experiencia en la que lo más importante son las relaciones entre las imágenes -relaciones que son más de interpenetración que de asociación-, aboga por la recuperación de la categoría de espacio en tanto contexto simbólico en donde el lenguaje juega un papel fundamental. De ahí que, para Benjamin, la filosofía sea experiencia absoluta deducida como lenguaje en el contexto sistemático simbólico.

${ }^{14}$ Esta insuficiencia es desarrollada por Benjamin en varios escritos. Sin embargo, es en "Sobre algunos motivos en Baudelaire" donde lo hace en relación con el poeta francés y lo extrapola a la filosofía afirmando que: "Si las condiciones de recepción de poemas líricos se han vuelto en verdad desfavorables, no resulta difícil imaginarse que la poesía lírica raramente conserva todavía contacto con la experiencia de los lectores. Tal conjetura quizá se dé por buena, pero tanto más embarazosa será sin duda la definición de lo que
} 
En esta medida, el sentido baudelariano de las correspondencias "se puede definir como el de una experiencia que busca establecerse al reparo de toda crisis" (Benjamin, 2008: 149). Por ello, un aspecto que rescata constantemente Benjamin al hablar de las correspondencias es el papel del recuerdo. No hay que olvidar que al tratar Berlín, el filósofo alemán ya ponía en evidencia la capacidad creativa y cognitiva del recuerdo, un recuerdo que se presenta como medio posibilitador de reacciones (Cfr. Benjamin, 2005: $\mathrm{J} 66,4,353$ y J79, 6, 374) y que no pertenece al terreno del tiempo, al de la autobiografía, sino al del espacio de los momentos, al del instante cuyo valor estriba en la posibilidad de su creación ${ }^{15}$. Esta atención por el detalle es lo característico de la mirada benjaminiana de lo urbano: "los detalles que crean el recuerdo, que crean instante, tienen siempre que ver con el espacio. Es este el que permite confeccionar un mapa, una cartografía en el recuerdo y en el modo de recordar, que posibilita superar el tiempo, romper la relación recuerdo-tiempo y dar lugar a una realidad plegada, asentada siempre en la conexión con lugares y con los detalles que los caracterizan más propiamente" (Hernández, 1996: 115).

Resulta, entonces, completamente comprensible la importancia que le dio Benjamin a la figura baudelariana del paseante, cuya forma paradigmática es la del flâneur y cuyo escenario no es otro que la gran ciudad. En El pintor de la vida moderna, Baudelaire enunciaba de esta manera las características del flâneur:

La muchedumbre es su dominio, como el aire del pájaro, como el agua el del pez. Su pasión y su profesión es el desposarse con las multitudes. Para el perfecto vagabundo, para el observador apasionado hay un inmenso goce en elegir domicilio en el número, y en lo ondulante, en el movimiento, en lo fugitivo y en lo infinito. Estar fuera de casa y, no obstante, sentirse en casa en cualquier parte. [...] Observador, paseante, filósofo, llamadle como queráis. A veces es poeta; más a menudo se aproxima al novelista o al moralista; es el pintor de las circunstancias y de todo cuanto las circunstancias sugieren eterno (Baudelaire, 1999: 352).

en ella pudo haberse transformado. Alcanzada esta situación, se interroga a la filosofía, y entonces se encuentra uno con un hecho peculiar. Desde los finales del siglo pasado, esta ha realizado unos intentos de apoderarse de la experiencia "verdadera", en contraposición a esa experiencia que se sedimenta en la existencia, normalizada y desnaturalizada, de las masas ya civilizadas" (Benjamin, 2008: 208).

${ }^{15}$ Para un desarrollo más profundo de este aspecto en relación a Berlín, véase: Hernández, 1996: 114-117. 
Así, el flâneur es aquel que se detiene ante el mundo que le rodea y, por un instante, ese instante a la vez efímero y determinante, es capaz de cruzar miradas antes de perderse en la multitud. Solo él sabe introducirse entre las calles y recorrer los laberintos en los que, como en Berlín, el espacio es recuperado a pesar de que siempre remita a la infancia:

La calle conduce al flâneur a un tiempo desaparecido. Para él, todas las calles descienden, si no hasta las madres, hasta un pasado que puede ser tanto más fascinante cuanto que no es su propio pasado privado. Con todo, la calle sigue siendo siempre el tiempo de una infancia. Pero ¿por qué la de su vida vivida? En el asfalto por el que camina sus pasos despiertan una asombrosa resonancia. La luz de gas, que desciende iluminando las losetas, arroja una luz ambigua sobre este doble suelo (Benjamin, 2005: M1, 2, 422).

El flâneur, entonces, se presenta como un descifrador de textos visuales y humanos cuyo recurso más importante es la ciudad, tal y como el propio Benjamin señala en El retorno del flâneur -texto que sirvió de epílogo a la obra de Hessel- al concebir la ciudad como recurso mnemotécnico del paseante solitario, en tanto que "ella incita más que la propia niñez y la juventud, más que su propia historia. Lo que ella abre es la inmensa escena de la flânerie, que nosotros creíamos definitivamente suprimida" (Benjamin, 1997: 216).

Por ello, es posible afirmar que en la obra de Benjamin el flâneur y la actividad de la flânerie se relacionan no solo con la observación y con la lectura, sino también con la producción: la producción de distintos tipos de texto. Esta idea, sin duda, la toma Benjamin de Hessel, para quien la flânerie "es una forma de lectura de la calle en la que las caras de las personas, los acristalamientos, los escaparates, las terrazas-café, los ferrocarriles, los automóviles y los árboles se convierten en letras con el mismo derecho, que juntas dan lugar a palabras, oraciones y páginas de un libro que es siempre nuevo" (Hessel, 1997: 21). Por esta razón se concibe que, en los escritos de Benjamin, esta figura sea algo más que una mera forma histórica en el contexto urbano, puesto que también funciona como metáfora de su propia metodología y, en consecuencia,

[...] una investigación de la flânerie como actividad debe explorar las actividades de la observación (incluida la escucha), la lectura (de la vida y de los textos metropolitanos) y la producción de textos. En otras palabras, la flânerie puede asociarse con una forma de mirar, observar (la gente, los 
tipos sociales, los contextos y las constelaciones sociales); una forma de leer la ciudad y su población (sus imágenes espaciales, su arquitectura, sus configuraciones humanas) $\mathrm{y}$, una forma de leer textos escritos (en el caso de Benjamin, tanto de la ciudad como del siglo XIX: como textos y de textos sobre la ciudad, incluso textos que funcionan como laberintos urbanos) (Frisby, 2007: 142).

Teniendo en cuenta lo analizado hasta el momento, es posible afirmar que la interpretación benjaminiana de Hessel y de Baudelaire revierte en un doble proceso - el de la recuperación del espacio y su consiguiente ampliación de la noción de experiencia- que es la base de la importancia filosófica de la ciudad en el planteamiento benjaminiano, así como la condición de posibilidad de la consideración estética del entorno urbano. Con ello, resulta perfectamente comprensible que Walter Benjamin se presente como el amante de las calles y de las historias urbanas y cotidianas; como el visionario de Simmel que desde su exterioridad es capaz de ser proximidad y distancia, así como el ojo que contempla y el paso que arraiga. De ahí que "sea preciso darse cuenta una y otra vez de que el comentario de una realidad (pues se trata aquí del comentario, de la interpretación de las singularidades) exige un método completamente distinto al de un texto" (Benjamin, 2005: N2, 1, 461).

De igual manera, este planteamiento enlaza con la ya señalada importancia de las correspondencias, que se presenta como una de las posibilidades de ampliación del concepto de experiencia, en tanto que "el verdadero método para hacerse presentes las cosas es plantarlas en nuestro espacio y no nosotros en el suyo" (Benjamin, 2005: H2, 3, 224). Es justo en esta búsqueda de posibilidades en la que Benjamin, al igual que Baudelaire, lleva a cabo sus diversos intentos con el hachís entre 1928 y 1934. No hay que olvidar que, en Baudelaire, la idea de las correspondencias se traslada a un plano sensible que tiene como correlato el efecto del hachís, el opio y el vino -los paraísos artificiales. Para Benjamin, esta vía se presenta como un despertar en el que

[...] los nombres de las calles son en estos casos como sustancias embriagadoras que amplían nuestra percepción, dotándola de múltiples niveles. La fuerza con la que nos ponen en ese estado podría llamarse su virtud evocadora; pero esto dice muy poco pues lo decisivo aquí no es la asociación, sino la interpenetración de las imágenes. También hay que acordarse de este hecho en el caso de ciertos fenómenos patológicos: el 
enfermo que por la noche recorre durante horas la ciudad olvidándose de volver a casa, quizá haya caído bajo el dominio de esta fuerza (Benjamin, 2005: P1a, 2, 517).

De esta manera, el hachís es visto como un medio en el que se percibe el efecto mórbido de la ciudad mediante la intensificación de los sentidos hasta que todas las correspondencias se hacen posibles. Así, la embriaguez, entonces, permite un contraste con la experiencia cotidiana "formando una especie de figura y siendo más memorable que usual" (Benjamin, 1984: 75). Y esto es así porque, para Benjamin, la embriaguez es la única experiencia en la que es posible asegurarse de lo más próximo y de lo más remoto, y en la que los objetos cobran nuevos significados. Las drogas, por tanto, traen consigo la potenciación del fenómeno de extrañamiento que ya había considerado en su experiencia urbana y que "Karl Krauss ha formulado con la hermosa frase siguiente: "Cuanto más de cerca se mira una palabra, más aparta ella misma la mirada", parece extenderse también a lo óptico» (Benjamin, 1984: 35), y que Benjamin expresa con la siguiente afirmación: "¡cómo hacen frente las cosas a las miradas!".

Así que, la mirada benjaminiana de lo urbano busca, inspirada en Hessel $\mathrm{y}$ en Baudelaire, sumergirse en la experiencia de lo cotidiano potenciando las relaciones entre los distintos objetos y fragmentos, llevado a cabo una revolución lingüística basada en el nombrar que tiene como resultado la transformación de lo pequeño en grande, de lo banal en importante, de lo insignificante en significante:

[...] la calle hizo posible que todas las palabras, o al menos una gran cantidad de ellas, fueran ascendidas a la nobleza del nombre -lo que antes no les ocurría más que a poquísimas, a una clase privilegiada de palabras-. Lo más ordinario para todos, la calle, fue lo que llevó a cabo esta revolución del lenguaje. - Mediante los nombres de las calles, la ciudad es un cosmos lingüístico (Benjamin, 2005: P3, 5, 521).

Teniendo esto en cuenta, resulta evidente que la revolución del lenguaje está íntimamente ligada a la nueva noción de experiencia, en tanto que -tal y como anticipara Hessel- tiene como resultado la constitución de la ciudad como un cosmos lingüístico que, a su vez, se presenta como la radicalización de la concepción de la ciudad como imagen en tanto que ahora pasa a ser texto. La experiencia es ampliada en el entorno urbano hasta la noción de lectura de la realidad que consiste no solo en asimilarla como si fuera un texto - un entramado- sino también en reconocer su diferencia. Esta nueva 
experiencia es descrita por Benjamin en Calle de dirección única (1926), donde afirma: "la ciudad se transformó en un libro que tenía entre mis manos y al que aún eché un par de ojeadas rápidas antes de que desapareciera de mi vista en el baúl del desván, por quién sabe cuánto tiempo" (Benjamin, 2002: 79).

La ciudad, por tanto, es como un palimpsesto, un paisaje amalgamado y constituido por diversas formas edificadas que, con el paso del tiempo, se superponen unas sobre otras y se transforman constantemente. Este palimpsesto es leído por Benjamin en múltiples capas atendiendo a los indicios aparentemente más triviales, a los desechos, a las migajas abandonadas, a los textos y a las imágenes en los que se inspira y que se presentan como entidades materiales de referencia. Como si se tratara de un diccionario cuyos nombres pueden ser leídos y en donde todo lenguaje es importante. De ahí que para el pensador alemán "todo discurso acerca del mayor o menor valor de los lenguajes [le] resulte inaceptable" (Benjamin, 2005: N, 1, 6, 460). Y es que, justamente, porque todo lenguaje es importante, la mirada de lo urbano se traduce en Benjamin en aceptar la invitación de Hessel y Baudelaire de establecer relaciones entre fragmentos que generen nuevos significados $\mathrm{y}$, al mismo tiempo, de "hacer instantáneas de las cosas" gracias a la constatación de que todos hemos sido y somos trayectoria. 


\section{Referencias}

Adorno, Th. W. (1998). Correspondencia (1928-1940). (Trads. J. Muñoz Vega y V. Gómez Ibáñez). Madrid: Trotta.

Adorno, Th. W. (1995). Sobre Walter Benjamin. (Trad. C. Fortea). Madrid: Ediciones Cátedra.

Arendt, H. (2001). Hombres en tiempos de Oscuridad. (Trads. C. Ferrari y A. Serrano). Barcelona: Gedisa.

Augé, M. (1998). El viaje imposible: el turismo y sus imágenes. Barcelona: Gedisa. AzúA, F. (1999). Baudelaire y el artista de la vida moderna. Barcelona: Anagrama. Baudelaire, Ch. (2001). Las Flores del Mal. (Trad. A. Holguín). Bogotá: Panamericana.

Baudelaire, Ch. (1999). Salones y otros escritos sobre arte. (Trad. C. Santos). Madrid: Visor.

Benjamin, W. (2005). Libro de los pasajes. (Trads. L. Fernández, I. Herrera y F. Guerrero). Madrid: Akal.

Benjamin, W. (2010). Obras IV, vol 1. (Trad. A. Brotons). Madrid: Abada

Benjamin, W. (2008). Obras I, vol 2. (Trad. A. Brotons). Madrid: Abada.

Benjamin, W. (2005). Libro de los pasajes. (Trads. L. Fernández, I. Herrera y F. Guerrero). Madrid: Akal.

Benjamin, W. (2002). Dirección Única. (Trads. J. del Solar y M. Allendesalazar). Madrid: Alfaguara.

Benjamin, W. (1997). El retorno del flâneur. Paseos por Berlín. (Trad. M. Salmerón). Madrid: Tecnos.

Benjamin, W. (1996). Escritos autobiográficos. (Trad. T. Rocha). Madrid: Alianza Universidad.

Benjamin, W. (1992). Cuadros de un pensamiento. (Trad. S. Mayer). Buenos Aires: Imago Mundi.

Benjamin, W. (1991). Diario de Moscú. (Trad. M. Delgado). Madrid: Taurus. 
Benjamin, W. (1990). Infancia en Berlín hacia 1900. (Trad. K. Wagner). Madrid: Alfaguara.

Benjamin, W. (1987). El Berlín demónico. (Trad. J. Parra). Barcelona: Icaria.

Benjamin, W. (1984). Haschisch. (Trad. J. Aguirre). Madrid: Taurus.

Benjamin, W. (1967). Ensayos escogidos. (Trad. H. Murena). Buenos Aires: Sur.

Benjamin, W. (1966). Briefe/Walter Benjamin. Frankfurt am Main: Suhrkamp

Benjamin, W. (1955). Schriften. Frankfurt am Main: Suhrkamp.

Buck-Morss, S. (1995). Dialéctica de la mirada, Walter Benjamin y el proyecto de los Pasajes. (Trad. N. Rabotnikov). Madrid: Visor.

Frisby, D. (2007). Paisajes urbanos de la modernidad. Exploraciones críticas. Buenos Aires: Prometeo 3010.

Gutiérrez Girardot, R. (2005). Dos naufragios en el mar incógnito de Walter Benjamin. Katatay. Año. I, No. 1-2. (pp. 106-111).

Gutiérrez Girardot, R. (1965). Walter Benjamin. Posibilidad y realidad de una filosofía poética. Ínsula. No. 221. (pp. 13-15).

Hernández SÁnChez, D. (1996). La creación del instante. La Balsa de la Medusa. No. 37. (pp. 114-117).

Hessel, F. (1997). Paseos por Berlín. (Trad. M. Salmerón). Madrid: Tecnos.

Kerik, C. (1993). En torno a Walter Benjamin. México: Universidad Autónoma Metropolitana de México.

Kohan, M. (2007). Zona Urbana: ensayo de lectura sobre Walter Benjamin. Madrid: Trotta.

Kohan, M. (2004). Zona Urbana: ensayo de lectura sobre Walter Benjamin. Buenos Aires: Norma.

PARdo, J. (1990). Las Formas de la Exterioridad. Valencia: Pre-textos.

SojA, E. (2008). Postmetrópolis. Estudios críticos sobre las ciudades y las regiones. (Trads. V. Hendel y M. Cifuentes). Madrid: Traficantes de Sueños. 